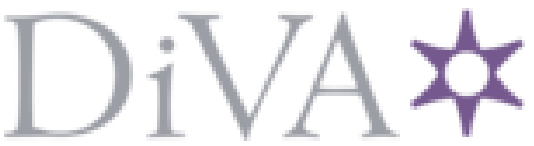

http://www.diva-portal.org

Preprint

This is the submitted version of a paper published in Journal of Information, Communication and Ethics in Society.

Citation for the original published paper (version of record):

Patrignani, N., Whitehouse, D. (2015)

Slow Tech: a roadmap for a good, clean and fair ICT

Journal of Information, Communication and Ethics in Society, 13(3/4): 268-282

https://doi.org/10.1108/JICES-05-2015-0014

Access to the published version may require subscription.

N.B. When citing this work, cite the original published paper.

Permanent link to this version:

http://urn.kb.se/resolve?urn=urn:nbn:se:uu:diva-401598 


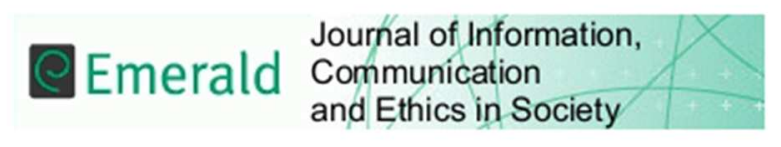

Slow Tech: A Roadmap for a Good, Clean and Fair ICT

\begin{tabular}{|r|l|}
\hline Journal: & Journal of Information, Communication \& Ethics in Society \\
\hline Manuscript ID: & Draft \\
\hline Manuscript Type: & Journal Paper \\
\hline Keywords: & $\begin{array}{l}\text { Slow Tech, Clean ICT, Proactive Computer Ethics, ETHICOMP, Fair ICT, } \\
\text { Good ICT }\end{array}$ \\
\hline \multicolumn{2}{|l}{} \\
\hline
\end{tabular}




\section{Slow Tech: A Roadmap for a Good, Clean and Fair ICT}

Keywords: Checklist, Clean ICT, Computer Ethics, ETHICOMP, Fair ICT, Good ICT, Human-Centred ICT, Proactive Computer Ethics, Roadmap, Slow Tech

\section{Introducing the general background to this paper}

The two-decade history of ETHICOMP conferences has done a great deal to build a community of people committed not only to the discussion of computer ethics but also to taking ethical actions with the aim of making a real difference in the information and communication technology (ICT) field.

This paper is a thought leadership piece and discussion document. It adopts a largely positive and constructive view of Slow Tech that concentrates its efforts on what is ethically desirable in terms of ICT.

Starting from a background overview of computer ethics, with a particular focus on the ETHICOMP series of conferences, the paper outlines the transitions that have taken place during the 65-year timespan of computer ethics (the paper concentrates on 1950 as the start-date of computer ethics, since this was the publication year of the book "The Human Use of Human Beings" by Wiener, who is considered to be the father of computer ethics (Wiener, 1950)). It places Slow Tech in the 20-year development of the ETHICOMP conference series, a period during which there has been a growing sense of how to make real ethical differences in the ICT world.

This paper introduces the basic features of Slow Tech - ICT that is good, clean, and fair. It highlights the complexity of today's ICT ecosystem, and advances arguments about how a Slow Tech approach can help to understand the relationships among these complicated interactions. It describes how a wide range of different stakeholders is involved in the ICT value chain. It outlines the activities involved in identifying - and, whenever possible, engaging - all the stakeholders present in an ICT network. It shows how to transform the identification of these stakeholders into a roadmap which could help implement the Slow Tech concept in practice. The paper then explores a number of challenges that need to be overcome before a Slow Tech approach can be adopted more fully. It concludes with a proactive, positive view of how Slow Tech can be applied. Therefore, the paper's main efforts are to lay out a series of actions that can help create an understanding of how an ICT stakeholders' network can be built, what might constitute a roadmap for future actions, and how to embed a more ethical perspective in general approaches related to ICT design, development, use and re-use. 


\section{Providing the computer ethics background to Slow Tech}

Slow Tech has developed as a notion largely throughout the last decade of the 20 years that ETHICOMP has been active. One of Slow Tech's strongest features is its positive, proactive outlook. This characteristic is similar to that seen in the development of the field of computer ethics over the previous 65 years.

The universal machine, foreseen by Turing in Cambridge in 1936-37, introduced human beings to an era in which a new field of applied ethics began to be needed. Some fourteen years later, Wiener first identified the "enormous potential for good and for evil" of the new information age (Wiener, 1950). The lack of ethical debate and ethical guidelines in the ICT field was later emphasised by Parker, who underlined the absence of ethics that occurred once people "cross[ed] the computer room's door" (Parker, 1968, pp.198-201). The first definition of computer ethics was provided by Maner who described the "new field" as one "that studies ethical problems aggravated, transformed or created by computer technology" (Maner, 1980). Work in the computer ethics field was to be based on the assumption that, with the use and application of computers, human beings would have to address their social and ethical implications. In his 1985 article, Moor introduced the term, policy vacuum: "... there is a policy vacuum about how computer technology should be used" (Moor, 1985, p.266). Later, computer ethics was considered as "... an academic field in its own right with unique ethical issues that would not have existed if computer technology had not been invented" (Maner, 1996, pp.137-154). The main justification for Maner's argument was based on the uniqueness of computers (i.e., their "lack of an effective analogy") (Maner, 1996, p.152).

Throughout the period from 1950 to 1985 , analyses of the social and ethical impacts of computing concentrated on the use of ICT once a technology had been developed rather than at earlier points in its life cycle, such as the analysis or design stages. Only with the introduction of the concept of socio-technical systems into the computer ethics debate by Johnson (1985), and the recognition that values are embedded in artefacts, did ethical design choices began to move towards centre stage. It was at this period that it became possible to address ethical issues related to computers, whether hardware or software programs, prior to their actual technical development.

\subsection{Focusing on the last 20 years of computer ethics}

The computer ethics debate began in Europe in 1995 when the Centre for Computing and Social Responsibility (CCSR) was first set up at De Montfort University in the United Kingdom. The centre's name is reminiscent of the 1981 launch of the Computer Professionals for Social Responsibility (CPSR) 
organisation in Palo Alto in the United States of America. With the start of the ETHICOMP series of conferences in that same year, a warm welcome was offered to scholars interested in joining the computer ethics community. As a result, 1995 signals the start of a new and more proactive computer ethics period. By the late 1990s, the essential ethical questions had become: What principles should drive designers of information systems? What can be done to ensure that computer systems are ethical even before they are actually developed?

Thus, the ethical importance of involving ICT users in design became more explicitly evident than it had been in earlier socio-technical developments (as explored in Stahl, 2007). The holistic approach of addressing social and ethical issues of computing, known as participatory design, entered the ICT world (Schuler and Namioka, 1993; Bjerknes and Bratteteig, 1995; Bødker, 1996). The era of ICT design driven by values, known as value sensitive design, was launched in the mid-2000s (Friedman et al., 2006; Van Der Hoven and MandersHuits, 2009). Many researchers contributed to these developments, and began to concentrate on the needs of human beings: they focused on issues of well-being and dignity, and fundamental values such as welfare, justice and human rights.

While some, more theoretical, recommendations for ICT designers emerged, like Floridi's notion of avoiding entropy in the infosphere (Floridi, 1999), the key, practical role of computer professionals became increasingly evident. In the software development area, efforts were made to encourage programmers to make a positive difference in terms of computer ethics: one example was the Software Development Impact Statement (SoDIS) process, in which the traditional concepts of risk analysis were extended beyond schedule and budget dimensions to include all the stakeholders affected by significant software projects (Gotterbarn and Rogerson, 2005).

Another leap in development took place towards the beginning of the second decade of the 21st century. Researchers began to examine technologies of the future. Many ethical design challenges were identified by a European Commission co-financed project called ETICA (ETICA, n/d). Clearly, the ICT world encompasses many technologies and applications. The ETICA consortium identified the characteristics and ethical challenges embedded in a range of ICT. The seven technologies that the project team investigated were: 1. Ambient Intelligence, 2. Augmented and Virtual Reality, 3. Future Internet, 4. Robotics and Artificial Intelligence and Affective Computing, 5. Neuroelectronics and Bioelectronics and Human-Machine Symbiosis, 6. Cloud Computing, 7. Quantum Computing. These emerging technologies were identified by the ETICA consortium as those which would challenge most dramatically the ethics of human beings, developers, policy-makers and users in the future. 
The ETICA project and its findings were at the forefront of the development of the field of Responsible Research and Innovation (RRI). One definition of RRI in ICT is based on three characteristics proposed by Von Schomberg, who described such innovation as:

"a transparent, interactive process by which societal actors and innovators become mutually responsive to each other with a view on the (ethical) acceptability, sustainability and societal desirability of the innovation process and its marketable products (in order to allow a proper embedding of scientific and technological advances in our society)" (Von Schomberg, 2011, p.9).

Other definitions have later been advanced (for example, Owen et al., 2012 and Stilgoe et al. 2013).

RRI in ICT is now an established research approach, promoted widely by the European Commission (European Commission, 2012). One of the more recent research results in this field is the Framework for Responsible Research \& Innovation in ICT (FRIICT, n/d). This approach emerged from a project funded by the United Kingdom's Engineering and Physical Sciences Research Council (EPSRC), and highlights the four practical dimensions of Anticipate, Reflect, Engage, and Act (AREA).

In general terms, therefore, Slow Tech heads in a similar direction to that of computer ethics since 1995. It introduces a positive and proactive approach to computer ethics that focuses on the ethically desirable. It insists on an assessment not only of the current implications of technologies but also their future impacts.

\section{Outlining the origins and main themes of Slow Tech}

Slow Tech was first introduced to the computer ethics community at ETHICOMP 2013 (Patrignani and Whitehouse, 2013). The authors have since examined in depth the concept's application to real-life scenarios and situations involving ICT vendors (Patrignani and Whitehouse, 2014a; 2014b).

Slow Tech suggests a long-term view of ICT that places human beings at its centre. Idealistically speaking, similar to the way in which the Italian Renaissance - with its focus on the importance of human beings - celebrated the end of the Dark Ages, Slow Tech can offer a new way of looking at ICT in the 21st century. Thus, Slow Tech aims to provide the next generation of ICT systems designers with a practical compass to help them make the kinds of ethical choices that are to be encouraged in computer system development. It encourages future 
designers - and a wide range of stakeholders - to think ahead in a long-term manner vis-à-vis computer technology (see especially sections 4 and 5 of this paper).

Slow Tech, as a term, has emerged from several different disciplinary areas that are characterised by various influences. At the beginning of the 21 st century, some authors saw Slow Tech as a form of ICT typified by a concern for reflection, mental rest, and mindfulness (Hallnäs and Redström, 2001). Slow Tech has also been used to describe the cultural and social impacts of mobile ICT devices (Kopomaa, 2007), and the investigation of problems that arise due to a lack of engineering robustness and to weaknesses in the general resilience of a variety of modern-day products (Price, 2009).

The origins of Slow Tech preferred by Patrignani and Whitehouse $(2013 ; 2014 \mathrm{a}$; 2014b) are, however, based on the inspiration provided by the Slow Food movement (Petrini, 2007). In this interpretation of Slow Tech, the three characteristics of good, clean, and fair that were previously applied directly only to food (Ibid, 2007; 2011), are adapted to ICT. Since these three sets of values are simply the transposition of concepts originally applied to Slow Food, they should not therefore be conceived as representing the highest among a more comprehensive hierarchy.

Illustrations and examples of each of these three aspects of ICT of good, clean, and fair ICT are to be found throughout the paper. Each of the three notions is, however, explained below in detail. In each case, a number of contemporary discussions are developed.

\section{Good ICT}

Good ICT is ICT that is developed by placing human beings centre-stage. Good ICT introduces an explicit awareness of a balance between the increasing speed of ICT and the more limited information processing speed of human beings. Thus, good ICT is to be designed by taking human limits into account.

To master these new forms of ICT design will require designers - and people more widely - to possess specific competences. These skills include humancomputer interaction, design-for-all, e-inclusion, and design methods such as participatory design. Placing a focus on these kinds of techniques will generate commitment to a future ICT that is designed and produced so as to become a desirable form of ICT.

Implicitly, it has been said that human beings are now entering a new era of hyper-connectivity where, almost fifty years after the limits of the planet were acknowledged (Meadows et al., 1972), the limits of the self are now being 
recognised (Dewandre, 2014); these ideas are more explicitly expressed in the European Commission's preoccupation with a human-centric digital age (European Commission, 2014, pp. 67-68).

In evolutionary terms, the human brain demonstrates two main features (Kahneman, 2011). One characteristic is dedicated to quick responses to environmental stimuli and threats, based mainly on sight, that involve direct, fast brain connections that do not need deep memories. The other characteristic is devoted to reason and reflection: it provides sufficient time for the human brain to establish connections among important deep memories and concepts. The first approach can be called fast thinking: it fits perfectly with the millions of pieces of information implicit in the digital revolution, with which human beings are immersed daily, and that are mostly based on pictures, videos, and short texts such as tweets and short messaging systems. It can be associated with Bauman's homo consumens, based on models of advanced e-markets and swarms of consumers continuously searching for goods (Bauman, 2007): experiences congruent with today's airline and train terminal passengers, passing rapidly through the associated shopping arcades. The second approach can be called slow thinking. In contrast, it needs silence, and is based on reading longer, elaborated texts, and on writing and speaking (Maffei, 2014).

\section{Clean ICT}

Clean ICT means ICT that takes into consideration the whole life cycle of the materials, energy, and products used to create, manufacture, power, and dispose of ICT (Patrignani and Kavathatzopoulos, 2012).

Clean ICT is a burgeoning, umbrella domain that encompasses the research, implementation and application of environmentally-friendly ICT. It extends these ideas further than does green IT, originally described by Murugesan (2008). ${ }^{1}$ Clean ICT involves a range of environmental impacts as wide as the materials involved in ICT manufacture; the impact of chip manufacturing processes; the power consumption of data centres, devices, and ICT applications; e-waste management, and recycling. It also pays growing attention to the recyclable-by-design approach.

In the past, the price of acquiring ICT devices has generally not taken into account the cost of the limits of the planet (Meadows et al., 1972; Schmitz and Graedel, 2010). However, the exponential evolution of ICT and the speed of acquisition and replacement of electronic devices are put into serious question by the consideration of planetary limits. It is becoming obvious that an in-depth

\footnotetext{
${ }^{1}$ Indeed, green ICT is probably the most investigated area of the three good forms of ICT involved in Slow Tech: see, for example, volume 13, issue 1 of the Journal of Information, Communication and Ethics.
} 
reflection process is needed - based on the slow thinking previously described on the very assumptions that underpin Moore's law (Moore, 1965). The question has been posed as to whether it is really feasible that micro-chips continue to grow exponentially in terms of their power (Patrignani and Kavathatzopoulos, 2012). Instead, scenarios and paradigms based on cycles are becoming more popular. Similar approaches, such as the circular economy, are seen in the field of the global economy (EMAF, 2014).

\section{Fair ICT}

Fair ICT is based on the equitable use of ICT. It bears certain similarities to the fair use initiative in the field of food consumption or fair trade more widely.

Fair employment is also a vital element of fair ICT, particularly ICT production that takes place under sound, humane conditions. Today's low cost of ICT is possible only at the excessive price paid in quality-of-life terms by employees who may even on occasions be slaves - in the ICT domain, working as they do at times in exploitative, unhealthy, insecure, and difficult work conditions. The social cost of manufacturing ICT, in factories where the working conditions are often unbearable for employees and contractors, is judged as unacceptable by commentators (Duhigg and Barboza, 2012).

In addition, the entire ICT value chain is often long and complex. Thus, the existence of one company often hides other companies, which may use even more unfair employment practices than the corporations which appear at the forefront. International policies now increasingly demand that companies - including ICT vendors - should improve their corporate behaviour. These policies stipulate that companies should no longer be able to hide the identities of their shareholders or management from public view, conceal the working conditions of their employees located in a variety of countries particularly in the developing nations, or fail to disclose their own employees', or contracted workers', lack of human rights (United Nations Global Compact, n/d).

In particular, a growing interest in corporate social responsibility guidelines on the part of the International Organization for Standardization promises progress towards improved ICT production (ISO, n/d): these guidelines could eventually mature into international standards.

\subsection{Examining the limits identified by Slow Tech}

Slow Tech adds to the existing discourse on RRI an awareness of a set of limits that can steer the design of future complex systems (Von Schomberg, 2011; Owen et al., 2012; Stilgoe et al. 2013). 
With its long-term view, Slow Tech introduces a view of ICT that combines a concern with three sets of limits: it takes into account the limits of human beings (it leads to good ICT), the planet (clean ICT), and the ICT value chain (fair ICT). Slow Tech is human-centred. It is built on a holistic approach that includes a fundamental criticism of the previously unquestioned assumption that ICT will experience no limits, operate exponentially faster, and always be financially cheaper. Today, it is known that human beings really do have limits. Faster information systems and applications are not always better for people: speed per se does not always improve the well-being, or so-called well-living, of human beings. Questioning the basis of fast technologies can indeed be a healthy approach (Lennefors, 2013).

Similar considerations already formed part of the reflections of the original founders of the computer ethics discipline (Wiener, 1950; Weizenbaum, 1976). For example, when he received the very first IFIP WG9.2 Namur Award, Professor Joseph Weizenbaum made a recommendation that was particularly in line with the Slow Tech approach, even although his comments pre-dated the movement's existence. On that occasion, he declared: "The key question is the control of the [sic] time. We would need more time to take some decisions. The rhythm of the computers and of the telecommunication systems is not the rhythm of time which is needed to take meaningful decisions" (Weizenbaum, 1991).

\section{Creating the ICT stakeholders' network implicit in Slow Tech}

Although Slow Tech is an apparently simple expression of the three concepts of good, clean and fair ICT, it nevertheless implies the need to understand the complex levels of the ICT life cycle through all the interactions present among the people engaged in the ICT stakeholders' network.

Slow Tech's emphasis is on the entire ICT life cycle and all the processes involved in the cycle. It investigates the whole value chain that is created in the course of, and as a result of, the production of ICT. Its perspective is independent of any specific technology. It is not limited to examining the implications of the technology's possible deployment. It approaches all new forms of ICT from the point of view of their development, from conception and design onwards. It starts from the consideration that ICT applications progress well beyond their use in a specific scenario or particular use case. Considering all the relevant stakeholders in the ICT life cycle helps other people, and the stakeholders themselves, to realise that the ICT world is a complex system, comprising many different actors.

An example of ICT stakeholders' network is composed of all the actors that are in some way involved with an ICT scenario (see Fig. 1 below). The network includes all the many different relationships among the stakeholders. While some of these 
relationships are bi-lateral, others are one-way only. While this figure focuses on stakeholders, it deliberately does not include commercial shareholders.

Among the most important stakeholders in an ICT network are: universities, computer engineers, and computer scientists (mainly because it is anticipated that it is from these institutions and professions that the next generation(s) of ICT designers will emerge); computer professionals' associations (whose codes of ethics cover the behaviour of those corporate and individual members that are in the main responsible for the design of current ICT systems); and ICT vendors (such as chip manufacturing companies, hardware, software, and telecommunications companies). The last of these actors are among the chief corporations that operate at a global scale in the ICT world (Patrignani and Whitehouse, 2014b).

In this example of a Slow Tech-related ICT stakeholders' network (see Fig. 1), users can recognise and acknowledge the collectivity of stakeholders involved in even very straightforward applications. The Slow Tech approach can be helpful in showing that all the processes involved in an action as apparently simple as exchanging correspondence via email can become good, clean, and fair.

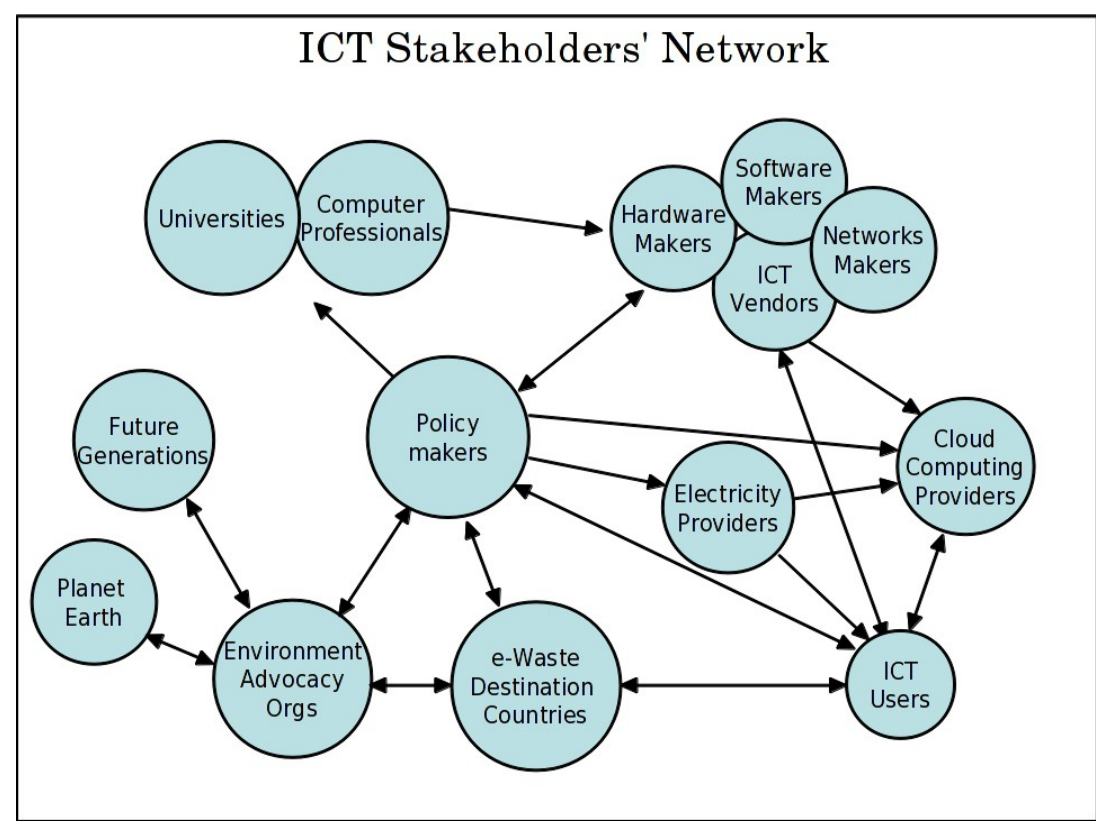

Figure 1. Slow Tech-related ICT Stakeholders' Network.

The Slow Tech approach - and its outlining of ICT stakeholders' networks enables people to ask the following kinds of questions: What are the principal steps in the ICT value chain? Who are the main actors? What are the relationships among these actors? How can the three Slow Tech characteristics good, clean, and fair ICT - be introduced in this complex ICT system? More 
specifically, how can Slow Tech make a difference to the computer ethics debate that is being investigated in-depth as a result of 20 years of ETHICOMP conferences?

All ICT is now interconnected. The main direction of travel is towards ICT as a service. The cloud is becoming the most important platform for ICT applications development and deployment. ICT users experience direct interactions with technology vendors and on-line communication and exchange with services, vendors and cloud providers. In terms of electricity providers, ICT is one of the industrial segments that experiences the highest power consumption - about 6$8 \%$ of total annual generation (Plepys, 2002; Mills, 2013). Hence, many of these questions are today concentrated around the issue of cloud computing. Therefore, the upcoming ETHICOMP 2015 conference shows a preoccupation with the challenges of both virtuality and the cloud. ${ }^{2}$

\section{Identifying stakeholder actions in a Slow Tech roadmap}

The Slow Tech approach is proposed as a compass for orienting people towards the design, production, and use of good, clean, and fair ICT.

The steps implicit in developing a roadmap for Slow Tech include identifying the ICT stakeholders (see Fig. 1: above). Among those stakeholder groups are universities, computer professionals, ICT vendors, ICT service providers including cloud computing providers, e-waste destination countries, the planet and future generations, and ICT end-users.

Each of the stakeholder groups is to be encouraged to identify for itself the positive, future actions that will take it in a Slow Tech direction. It is therefore important to explore in detail how the different sets of stakeholders can each play a role in supporting a Slow Tech vision, both individually and collectively. The following sub-sections outline a number of potential suggestions for action for the diverse stakeholders.

\section{Universities and computer professionals}

Universities could introduce new subjects, such as "Social and ethical implications of computing", into the appropriate educational levels of computer science curricula. Participatory design approaches could be both promoted and taught in order to prepare generations of future computer professionals to have an understanding of Slow Tech. Computer professionals could introduce Slow Tech into their code of ethics as a basic set of guidelines.

\footnotetext{
${ }^{2}$ http://www.dmu.ac.uk/research/research-faculties-and-institutes/technology/centre-forcomputing-and-social-responsibility/ethicomp2015.aspx, accessed 19 May 2015.
} 


\section{ICT vendors}

Hardware manufacturers and ICT vendors could make serious efforts to apply corporate social responsibility measures. For example, they could do so by developing or using recyclable-by-design hardware, minimising the power consumption of devices, and checking the entire supply chain of their electronic components from the Slow Tech point of view, particularly in terms of clean and fair. In policy terms, increasingly, companies can now be considered as accountable or responsible for the behaviours of their suppliers.

\section{ICT service providers, including cloud computing providers}

As Fig 1 (above) showed, among the most important of contemporary stakeholders are cloud computing providers and cloud brokers. ICT services delivery organisations provide a link through which organisations act as intermediaries in the relationship between ICT users and ICT infrastructure. Although ICT infrastructure is a much more comprehensive notion, it is increasingly being examined from the perspective of the cloud (e.g., Patrignani, 2015).

Some possible actions in the Slow Tech direction are concentrated around how to provide a trusted and sustainable cloud for end-users in which they can rely on a solid, open technology environment. This could be done, for example, by providing standard data formats to users without them being drawn into lock-in situations, offering them low power consumption data centres, and exposing them to information about the sources of electricity needed to run their devices and equipment.

\section{e-Waste destination countries}

The countries which act as dumping sites for ICT products that are no longer used - among them countries in Africa and Asia - now pay the highest economic, social and environmental price for their involvement in the ICT value chain. Contemporarily, as e-waste destination countries, they have become the victims of an ICT value chain that fails to take the environment into account. In the future, countries will be encouraged to be more attentive to environmental questions, by requesting and applying new international norms to control ewaste.

\section{Policy-makers}

Policy-makers are able to apply the Slow Tech paradigm as a general ethical approach to ICT. They can do so when they prepare and define new guidelines and norms. This decision-making can have implications at many different levels of society, from the international to the national, and from the regional to the local. Initiatives undertaken by international, non-governmental organisations or 
civil services, such as the European Commission, could have an impact on the behaviour of the whole ICT industry (European Commission, 2011).

\section{Planet and future generations}

Some of the most recently recognised stakeholders in the ICT network are the planet and future generations. Previously, the other stakeholders - such as hardware manufacturers, ICT vendors, ICT end-users, policy-makers, and even entire countries - have preferred to remain, consciously or unconsciously, unaware and ignorant of the implications of their activities for either the planet or the next generations. In this sense, they are similar to the tobacco companies in the 1930s through to the 1960s that ignored the health implications of smoking. Now, thanks to the work of various environmental advocacy organisations - that provide market observatories and Slow Tech cleanness assessments - the needs of the planet are being brought to the fore. A growth in awareness is expanding the understanding of the implications of ICT-related actions some seven generations into the future (Lyons, 1980). It is today's grandparents, parents and young people - working together in an intergenerational collaboration - who will encourage forms of ICT that no longer pose harm to future generations. As a result, the livelihoods and welfare of many future generations will be safeguarded.

\section{ICT end-users}

For ICT end-users, Slow Tech implies two major trends. As consumers, on the one hand, it means grasping the opportunity to experience and enjoy humancentred ICT; on the other hand, it requires being open to participating more fully in actual ICT developments, and paying more attention to the meaning of devices, their life cycles, power consumption, and recycling. In many markets (Littler, 2008) - the fields of textiles, fashion, and clothing are obvious examples - consumer awareness is beginning to ensure that pressure is placed on the providers of certain goods and services so that they shift into more ethical directions. ICT devices are a potential next industry in which fair trade notions will become more important: social enterprises such as FairPhone - in existence since 2010 - provide initial examples of this trend (FairPhone, 2015). Customers now demand that there should be greater transparency about the value chains underpinning particular products or services, and that all a company's business partners should be identified.

\subsection{Shifting from a Slow Tech roadmap towards a Slow Tech checklist}

It is crucial to consider how such a list of independent actions, described above, can be converted into a step-by-step, time-based set of activities that could be handled in a complete and logical manner. All of the steps that have been outlined could be arranged in the form of roadmap, complete with a set of actions 
and timelines. Compliance with such a Slow Tech roadmap could be based on outlining a collection of tests or checklists that can be applied to the whole ICT value chain. This activity has not yet taken place, and is not explored in detail in this paper.

Taking only the domains of clean and fair ICT as examples, however, the types of considerations to be listed in such a checklist could include: the sources of raw materials used to build integrated circuits; the processes involved in microprocessor production; the working conditions of employees in hardware suppliers' plants; the contractual arrangements made by software developers; the methodologies used in developing ICT applications; the power consumption of data centres; and the eventual physical (waste) destination of end-users' devices at the end of their technological lives.

Such a checklist will of necessity have to evolve continuously and transparently. By evaluating the responses to such a checklist of probing questions, it would be feasible to develop an ethical assessment of each ICT value chain, built according to Slow Tech principles. The procedure could later be developed into a set of guidelines (like those of the ISO (n/d)) or standards and certification.

If end-users were to become more aware about checking carefully the existence of Slow Tech certification when they acquire ICT goods, services or applications and were thus to show their willingness to become more conscientious consumers - then even the giant ICT companies might be more ready to produce responsible technologies and disclose information that is appropriate and relevant to their supply chains and production chains.

\section{Identifying the challenges that lie ahead for Slow Tech}

It is clearly important to make a start on building the proposed foundations of this Slow Tech roadmap. However, it is nevertheless salutary to recognise the difficulties and challenges that could lie ahead as such a roadmap is developed. A brief overview of a number of challenges follows.

One of the principal challenges lies in investigating and reconfiguring ICT value chains, and addressing markets that are already global networks. In 2014, the ICT market was already estimated to be around 3,800 billion US dollars (Gartner, 2014). Undoubtedly, such a gigantic set of market-makers cannot be challenged without first taking into account the relevant vested interests, sticking points, the impact of globalisation, the market pressures, and any hindrances to progress. 
Other challenges involve not only naming specifically the wide range of stakeholders, but also getting them to meet up and join within a network, group or platform. Together, the stakeholders need to recognise the super-ordinate, over-arching harms that are manifest in the production, manufacturing or use of ICT, particularly in relation to the future of the planet and, hence, to future generations.

It may also be challenging for all concerned to admit the way in which these potential harms affect both the developed world and the emerging economies. For this reason, the engagement of various international organisations, such as the European Commission, the International Federation for Information Processing, the International Labour Organisation, and the International Organization for Standardization, may prove useful in addressing the short-termism and lack of foresight prevalent in the ICT industry which could be deemed as being at least partly attributable to the actions of shareholders involved in commercial organisations.

Examples illustrative of how such challenges may be overcome include how similar difficulties have been, and are being, handled in the automotive market and the digital devices markets. First, the automotive market - after more than one hundred years of operation - is realising the need to rethink its role and its impact on the environment. The result - which is still in progress - involves the design and development of electric cars and recyclable-by-design vehicles. Second, the digital devices' market is part of complex, networked system in which even a small incident can trigger a larger chain of events. As an illustration: a simple newspaper article about the working conditions of people producing ICT smartphone and tablets can enable a public discussion among end-users and policy-makers: it can result in factory inspections being conducted by an independent, international body (Fair Labor Association, 2013). These kinds of developments can produce indirect, and direct, pressures on ICT vendors that could eventually alter the ways in which technologies are built, and the kinds of contractual arrangements made with employees and contractors.

\section{Concluding this overview of Slow Tech}

This paper takes the Slow Tech concept further than its earlier introduction (Patrignani and Whitehouse, 2014a). It examines the way in which Slow Tech has developed, and its similarities with other trends that have lasted the 20-year lifetime of the ETHICOMP series of conferences and the 65-year history of computer ethics in general. Looking back over the 20-year history of ETHICOMP shows just how far computer ethics has already progressed. 
Similar to other ethical approaches - like RRI and SoDIS (Gotterbarn and Rogerson, 2005; Von Schomberg, 2011; Owen et al., 2013; Stilgoe et al, 2013; Stahl et al., 2014) - Slow Tech aims to provide useful tools that support the translation of ethical debates into real actions in a number of concrete ICT scenarios. Slow Tech's focus will in the future lie in the development of an ICT stakeholders' network, a roadmap, and an action checklist.

Over the next two decades, the ICT future is likely to be even more demanding in terms of the difficulties to be faced, and the Slow Tech actions that will need to be taken. While the journey ahead is likely to be long and challenging, Slow Tech's foundation means that it is worthwhile, indeed essential, for stakeholders to start constructing a Slow Tech roadmap together. This strenuous ethical journey into the future can be alleviated by people having a good compass and a sound roadmap in their hands.

With the concerted effort of a growing network of people - like the ETHICOMP community - who are involved in the study and research of responsible research and innovation in ICT and the social and ethical issues of ICT, the ICT industry could make a huge leap forward towards good, clean and fair ICT.

\section{Acknowledgements}

Thanks are due to various attendees at ETHICOMP 2014 conference workshops; the anonymous reviewers of a paper submitted to the ETHICOMP 2014 conference; and the similarly anonymous reviewers of the Journal of Information, Communication and Ethics in Society for their helpful comments and constructive criticisms of earlier versions of this paper.

\section{References}

Bauman, Z. (2007). Homo Consumens. Lo sciame inquieto dei consomatori e la miseria degli esclusi, Centro Studi Erickson, Trento.

Bjerknes G., Bratteteig T. (1995). User Participation and Democracy. A Discussion of Scandinavian Research on System Development, Scandinavian Journal of Information Systems, vol 7 no 1, April 1995, pp. 73-98.

Bødker, S. (1996). Creating conditions for participation: Conflicts and resources in systems design, Human Computer Interaction, 11 (3): 215-236.

Dewandre N. (2014). Policy-making in a hyperconnected era: Game over for modernity?, Presentation at RRI/SSH in ICT related parts of WP1415, InfoDay, Bruxelles, Belgium, 21 January 2014. Available at http://caps2020.eu/wp-content/uploads/2014/02/Dewandre_CAPS.pdf, accessed 19 May 2015.

Duhigg, C., Barboza, D. (2012). In China, Human Costs Are Built Into an iPad, 
New York Times, January 25, 2012.

EMAF (2014). Towards the circular economy, Vol.3, Ellen MacArthur Foundation, http://www.ellenmacarthurfoundation.org/business/reports, accessed 19 May 2015.

ETICA (n/d). ETICA stands for 'Ethical Issues of Emerging ICT Applications', http://www.etica-project.eu, accessed 19 May 2015.

European Commission (2011), A renewed EU strategy 2011-2014 for Corporate Social Responsibility, (COM(2011) 681 final), http://eur-

lex.europa.eu/LexUriServ/LexUriServ.do?uri=COM:2011:0681:FIN:EN:PDF, accessed 19 May 2015.

European Commission (2012), Responsible Research and Innovation: Europe's ability to respond to societal challenges, http://ec.europa.eu/research/sciencesociety/document_library/pdf_06/responsible-research-and-innovationleaflet_en.pdf, accessed 19 May 2015.

European Commission (2014), Horizon 2020, Work Programme 2014-2015. 5. Leadership in enabling and industrial technologies. i. Information and Communication technologies. Revised.

http://ec.europa.eu/research/participants/data/ref/h2020/wp/2014_2015/main/ h2020-wp1415-leit-ict_en.pdf, accessed 19 May 2015.

FairPhone (2015). http://www.fairphone.com, accessed 19 May 2015.

Fair Labor Association (2013). Final Foxconn Verification Status Report, Fair Labor Association, December 2013, retrieved from http://www.fairlabor.org/report/final-foxconn-verification-status-report, accessed 19 May 2015.

Floridi L. (1999). Information ethics: On the philosophical foundation of computer ethics, Ethics and Information Technology 1: 37-56, Kluwer Academic Publisher.

Friedman, B., Kahn, H.K., Jr., Borning, A. (2006). Value Sensitive Design and Information Systems, in P. Zhang and D. Galletta, Human-Computer Interaction and Management Information Systems: Foundations, M.E. Sharpe.

FRRIICT (n/d). Framework for Responsible Research \& Innovation in ICT, Retrieved from http://responsible-innovation.org.uk/torrii, accessed 19 May 2015.

Gartner (2014). Gartner Says Worldwide IT Spending on Pace to Reach $\$ 3.8$ Trillion in 2014, January 6, 2014, http://www.gartner.com/newsroom/id/2643919, accessed 19 May 2015.

Gotterbarn, D., Rogerson, S. (2005). Responsible Risk Assessment with Software Development: Creating the Software Development Impact Statement, Communications of the Association for Information Systems, Vol. 15, Art.40. Hallnäs, L, Redström, J. (2001). Slow Technology; Designing for Reflection, Journal of Personal and Ubiquitous Computing, Vol.5, Issue 3, SpringerVerlag, pp.201-210. 
ISO (n/d). ISO 26000 - Social responsibility, http://www.iso.org/iso/home/standards/iso26000.htm, accessed 19 May 2015. Johnson, D. (1985). Computer Ethics, First Edition, Englewood Cliffs, NJ: Prentice-Hall.

Kahneman, D. (2011). Thinking, Fast and Slow. Farrar, Straus and Giroux. Kopomaa, T. (2007). Affected by the Mobiles: Mobile Phone Culture, Text Messaging, and Digital Welfare Services. In Pertierra, R. (Ed.) The Social Construction and Usage of Communication Technologies: Asian and European Experiences, Quezon City, University of the Philippines Press, pp.48-59.

Lennefors, T.T. (2013). Information society: Sustainability, speed and technomass in: Bynum T.W., Fleishman W., Gerdes A., Nielsen G.M., Rogerson S. (eds.), The possibilities of ethical ICT, ETHICOMP 2013 Proceedings. p. 384-390, Kolding: Print \& Sign University of Southern Denmark, ISBN: 978-8792646-72-9, Kolding, Denmark, 12-14 June 2013.

Littler, J. (2008). Radical Consumption. Shopping for change in contemporary culture. Open University Press.

Lyons, O. (1980). An Iroquois Perspective. In Vecsey, C., Venables, R.W. (eds.) American Indian Environments: Ecological Issues in Native American History. Syracuse University Press, New York, pp. 171-174.

Maffei, L. (2014). Elogio della lentezza, Il Mulino, Bologna.

Maner, W. (1980). Starter Kit in Computer Ethics, Hyde Park, New York: Helvetia Press and the National Information Resource Center for Teaching Philosophy.

Maner, W. (1996). Unique Ethical Problems in Information Technology, Science and Engineering Ethics, 2 (2), pp. 137-154.

Meadows, D.H., Meadows, D.L., Randers, J., Behrens III, W.W. (1972). The Limits to Growth, Universe Books.

Mills, M.P. (2013). The Cloud Begins with Coal. Big Data, Big Networks, Big Infrastructure, and Big Power. An Overview of the Electricity used by the Global Digital Ecosystem, August 2013, http://www.tech-pundit.com/wpcontent/uploads/2013/07/Cloud_Begins_With_Coal.pdf?c761ac, accessed 19 May 2015.

Moor, J. (1985). What Is Computer Ethics?, Metaphilosophy, 16(4): 266-75.

Moore, G.E (1965). Cramming More Components onto Integrated Circuits, Electronics, pp. 114-117, April 19, 1965.

Murugesan, S. (2008). Harnessing Green IT: Principles and Practices, IT Professional, 10 (1), pp. 24-33, January/February.

Owen, R., Macnaghten, P.M., Stilgoe, J. (2012). Responsible Research and Innovation: from Science in Society to Science for Society, with Society. Science and Public Policy, 39 (6), pp751-760.

Parker, D. (1968). Rules of Ethics in Information Processing, Communications of the ACM, 11: 198-201. 
Patrignani, N. (2015). Cloud Computing: the Ultimate Centralized ICT Architecture? Presentation at workshop on ethics and social accountability of ICT - The challenges of virtuality and the cloud: the implications of social accountability and professional ethics, Middlesex University, London, 23 February 2015.

Patrignani, N., Kavathatzopoulos, I. (2012). Is post-Turing ICT sustainable? in ICT Critical Infrastructure and Society, Hercheui, M.D., Whitehouse, D., McIver, W., Phahlamohlaka, J. (eds.), Proceedings of the 10th IFIP TC 9 International Conference on Human Choice and Computers, HCC10 2012, Amsterdam, The Netherlands, September 27-28, 2012, Springer, Heidelberg, pp. 183-191.

Patrignani, N., Whitehouse, D. (2013). Slow Tech: towards a good, clean and fair ICT in: Bynum T.W., Fleishman W., Gerdes A., Nielsen G.M., Rogerson S. (eds.), The possibilities of ethical ICT, ETHICOMP 2013 Proceedings. p. 384390, Kolding: Print \& Sign University of Southern Denmark, ISBN: 978-8792646-72-9, Kolding, Denmark, 12-14 June 2013.

Patrignani, N., Whitehouse, D. (2014a). Slow Tech: a quest for good, clean and fair ICT, Journal of Information, Communication and Ethics in Society, Vol.12, n.2, 2014, ISSN: 1477-996X, pp. 79-92.

Patrignani, N., Whitehouse, D. (2014b). Slow Tech: The bridge between computer ethics and business ethics in: Kimppa, K., Whitehouse, D., Kuusela, T., Phahlahmohlaka, J. (eds.) ICT and Society. HCC11 2014. IFIP AICT 386. IFIP International Federation for Information Processing. Springer-Verlag: Heidelberg and Berlin, pp. 92-106.

Petrini, C. (2007). Slow Food Nation: Why our Food should be Good, Clean and Fair, Rizzoli Intl. Pub., Milano, Italy.

Petrini, C. (2011). Buono, Pulito e Giusto. Principi di Nuova Gastronomia, Einaudi, Torino, Italy.

Plepys A. (2002). The grey side of ICT, Environmental Impact Assessment Review, Elsevier.

Price A. (2009). Slow-tech: Manifesto for an Over-wound World, Atlantic Books. Schmitz, O.J., Graedel, T.E. (2010). The Consumption Conundrum: Driving the Destruction Abroad, http://e360.yale.edu/feature/the_consumption_conundrum_driving_the_destr uction_abroad/2266/, accessed 19 May 2015.

Schuler, D., Namioka, A. (eds.) (1993). Participatory Design: Principles and Practices, Erlbaum.

Stahl, B.C. (2007). ETHICS, Morality and Critique: An Essay on Enid Mumford's Socio-Technical Approach, Journal of the Association for Information Systems, Special Issue, Vol. 8, Issue 9, pp.479-490.

Stahl, B.C., Eden, G., Jirotka, M. and Coeckelbergh, M. (2014). From Computer Ethics to Responsible Research and Innovation, Information \& Management, Vol.51, Issue 6, September 2014, pp.810-818, Elsevier. 
Stilgoe, J., Owen, R., Macnaghten, P. (2013). Developing a framework for responsible innovation. Res. Policy. 42, pp1568-1580.

United Nations Global Compact (n/d). UN Global Compact, http://www.unglobalcompact.org, accessed 19 May 2015.

Van Der Hoven J., Manders-Huits N. (2009). Value Sensitive Design, in Olsen, J.K.B., Pedersen, S.A., Hendricks, V.F. (eds.), A Companion to the Philosophy of Technology, Blackwell Publishing.

Von Schomberg, R. (2011). Towards Responsible Research and Innovation in the Information and Communication Technologies and Security Technologies Fields, European Commission, European Research Area, Science in Society, http://ec.europa.eu/research/science-society/document_library/pdf_06/meprapport-2011_en.pdf, accessed 19 May 2015.

Weizenbaum, J. (1976). Computer Power and Human Reason: From Judgment To Calculation, Freeman.

Weizenbaum, J. (1991). Information: Explosion - Implosion? Namur Award 1991 Lecture by Prof. J. Weizenbaum.

https://staff.info.unamur.be/jbl/IFIP/NA1991_Lecture.html, accessed 19 May 2015.

Wiener, N. (1950). The Human Use of Human Beings: Cybernetics and Society. Houghton Mifflin, Boston, 1950; 2nd ed. Doubleday Anchor, 1954. 